\title{
Reward System Components in Addictive Disorders
}

\author{
Behzad Saberi* \\ Medical Research, Iran
}

*Corresponding author: Behzad Saberi, Medical Research, Iran.

Received Date: June 01, 2019

Published Date: July 18, 2019

\section{Mini Review}

There are some important components in the reward system include insular, prefrontal and orbitofrontal cortexes, ventral pallidum, nucleus accumbense, amygdala and ventral tegmental area. The origin of the dopaminergic reward system is the ventral tegmental area which is the dopaminergic neurons location and can activate the ventral striatum by sending the dopaminergic neurons axons to that. Ventral tegmental area influences the behavior and actions which would lead to 'better than expected' result and will be repeated in the future more frequently. Such result causes the 'positive prediction error' [1-5].

Feelings of 'wanting' and 'liking' occur by the neurons in the ventral striatum and nucleus accumbens which contain neurons that are under opioid neurotransmission influence and cause affective pleasure -liking feeling -and neurons which are activated by the ventral tegmental dopaminergic stimulation and lead to specific actions motivation - wanting feeling. Similar to the ventral striatum, ventral pallidum is involved in such affective and motivational processes. Emotional evaluation of the related stimulations and consequently survival and preservation of the species and silence attribution to stimulations which would be important, is the role which amygdala plays in this regard same as the axons of the prefrontal cortex neurons which would activate the ventral tegmental area. The insular and orbitofrontal cortexes play the important role in stimulus reward value stimulation. Long-term motivations and aims development are the prefrontal cortex role. Ventral striatum and ventral tegmental area's tonic baseline activity are induced by a positive evaluation of the real situation regarding long-term aims. Reduced craving for alcohol and cocaine achieved by direct current stimulation and transcranial magnetic stimulation of the prefrontal cortex of the alcohol and cocaine addicted patients [6-10].

The key system for all addictive disorders which is the dopaminergic reward system leads to subjective experience and behavioral alterations. Patient's motivations and cognitions would be dominated almost completely by the addictive activities. It is necessary to understand the basic mechanisms involved in the reward system so that dealing with addictive disorders during clinical practice can be done more precisely and with achieving better clinical results [11-13].

\section{Acknowledgement}

None.

\section{Conflict of Interest}

No conflict of Interest.

\section{References}

1. Berridge KC, Robinson TE (2003) Parsing reward. Trends Neurosci 26(9): 507-513.

2. Grüsser SM, Thalemann CN, Verhaltenssucht (2006) $1^{\text {st }}$ edn. Bern: Verlag Hans Huber.

3. Bayer HM, Glimcher PW (2005) Midbrain dopamine neurons encode a quantitative reward prediction error signal. Neuron 47(1):129-141.

4. Cromwell HC, Berridge KC (1993) Where does damage lead to enhanced food aversion: the ventral pallidum/substantia innominata or lateral hypothalamus? Brain Res 624(1-2): 1-10.

5. Karreman M, Moghaddam B (1996) The prefrontal cortex regulates the basal release of dopamine in the limbic striatum: an effect mediated by ventral tegmental area. J Neurochem 66(2): 589-598.

6. Camprodon JA, Martinez-Raga J, Alonso-Alonso M, Shih MC, PascualLeone A (2007) One session of high frequency repetitive transcranial magnetic stimulation (rTMS) to the right prefrontal cortex transiently reduces cocaine craving. Drug Alcohol Depend 86(1): 91-94.

7. Berridge KC (2003) Pleasures of the brain. Brain Cogn 52(1): 106-128.

8. Davey CG, Yücel M, Allen NB (2008) The emergence of depression in adolescence: development of the prefrontal cortex and the representation of reward. Neurosci Biobehav Rev 32(1): 1-19.

9. American Psychiatric Association (2013) Diagnostic and statistical manual of mental disorders. Arlington.

10. Beck A, Schlagenhauf F, Wüstenberg T, Hein J, Kienast T, et al. (2009) Ventral striatal activation during reward anticipation correlates with impulsivity in alcoholics. Biol Psychiatry 66(8): 734-742. 
11. Di Chiara G, Bassareo V (2007) Reward system and addiction: what dopamine does and doesn't do. Curr Opin Pharmacol 7(1): 69-76.

12. Reuter J, Raedler T, Rose M, Hand I, Gläscher J, et al. (2005) Pathological gambling is linked to reduced activation of the mesolimbic reward system. Nat Neurosci 8(2):147-148.
13. Blood AJ, Iosefescu DV, Makris N, Perlis RH, Kennedy EN, et al. (2010) Microstructural abnormalities in subcortical reward circuitry of subjects of subjects with major depressive disorder. PLoS One 5(11): e13945. 